\title{
The Impact of Bacterial Infections on Human Spermatozoa
}

\author{
Ali Zeyad ${ }^{1}$, Houda Amor ${ }^{1}$, and Mohamad Eid Hammadeh ${ }^{1 *}$
}

\begin{abstract}
Male urogenital tract infection (UTI) is one of the most important causes of male infertility, being associated with $8 \%-35 \%$ of male infertility. Pathogenic bacteria may interfere with infertility treatment involving the application of in vitro fertilization. Microorganisms might affect the spermatozoa function in different ways: $(a)$ By direct contact on sperm cells; by the help of some organelles such as pili; causing agglutination of motile sperm, reducing ability of the acrosome reaction, and also causing alterations in cell morphology. (b) Trigger a local inflammatory reaction leading to increase in reactive oxygen species (ROS). (c) Induction of sperm autoantibodies. $(d)$ Production of cytotoxic factors. (e) Infection treatment with antibiotics for long time may lead to defect in the sperm. The most frequently isolated bacteria from semen samples include Staphylococcus aureus, Escherichia coli, Streptococci, Klebsiella sp, Mycoplasma hominis, Chlamydia trachomatis and Enterococcus faecalis. The infection with these bacteria has significantly negative effect on sperm parameters and DNA integrity. DNA fragmentation may cause infertility, miscarriage, and birth defects in offspring. Therefore it may be a more objective marker of sperm function. The exact molecular mechanism of how bacteria affect chromatin and sperm nuclear protein still unknown. The bacterial infections lead to premature emergence of histone H3 methylation at lysine 79 (trimethylated H3K79) and hyperacetylated H4 which simultaneously occurred with transition protein TNP1. In mammals, reduced levels of histone H4 hyperacetylation correlates with impaired fertility. Further researches on this topic are necessary.
\end{abstract}

Keywords: Bacterial Infection, Sperm proteins, PRM1/PRM2 ratios

\section{Introduction}

The infertility is common clinical problem. Sixty percent of patients treated with assisted reproductive technology (ART) had suffered inflammation or infection. There is direct relation between male infertility and genital tract infection, this relation represents important problem in contemporary andrology (1).

The bacteria responsible for semen infection may originate from the urinary tract or be sexually transmitted (1). The unhygienic sex represents important way for permeation of such these bacteria to genital tract.

The male reproductive system includes 2 testicles, accessory reproductive ducts and secretory glands (seminal vesicles and prostate gland). Testicles are components of reproductive and the endocrine system. Therefore, the 2 main functions of the testicles are: producing sperm (approximately 1 million per hour) and male sex hormones (e.g. testosterone) (2).

Spermatogenesis occurs within the seminiferous epithelium on the surface of the sertoli cells. Sperm pass in different stages of maturation before a gamete can leave the testis. These processes include mitotic multiplication and propagation of the spermatogonial stem cells (SSCs), meiotic division of genetic material and maturation of spermatozoa (3).
Human normal semen consists of sperm and fluids from each of the vas deferens, the seminal vesicles, the prostate gland and the mucous glands, especially the bulb urethral glands. Seminal vesicle fluid represents $60 \%$ of the semen where serves to wash the sperm out of the ejaculatory duct and urethra (4).

According to the fifth edition of manual for semen analysis of WHO, 2010 (5), the normal values of semen determined as follow:

sperm concentration is $\geq 15 \times 10^{6} / \mathrm{mL}$ and the total sperm count is $\geq 39 \times 10^{6} /$ ejaculate, $\geq 40 \%$ motility, $32 \%$ progressive motility, $\geq 4 \%$ normal forms and white cell count, $<10^{6} / \mathrm{ml}$ of ejaculate.

\section{Sperm Chromatin and Nuclear Protein}

Normally, the sperm chromatin is a highly compact structure consisting of DNA and heterogeneous nucleoproteins. It is compacted and insoluble in order to protect DNA and facilitate transport of the paternal genome through the male and female reproductive tracts (6).

Sperm chromatin differs from somatic cells in both constituents and arrangement. Human sperm nuclei contain approximately $85 \%$ protamines and $15 \%$ histones in their nucleoprotein component, (7). Protamines, which

Received 16 November 2016, Accepted 25 April 2017, Available online 4 June 2017

${ }^{1}$ Department of Obstetrics and Gynaecology, IVF \& Andrology Laboratory, University of the Saarland, Homburg/Saar, Germany University of the Saarland, Homburg/Saar, Germany.

*Corresponding Author: Mohammad Eid Hammadeh, Tel: +49-68411628117, Fax: +49-68411628443, Emails: mehammadeh@yahoo.de, mohamad.eid.hammadeh@uks.eu 
are half the size of histones, replace the most of histone during maturation process and the chromatin becomes condensed unique supercoiled structure named toroids (8). Protamine 1 and 2 (P1\&P2) are the most nuclear proteins in human sperm nucleus packaging the sperm DNA, where P1 is produced as a mature protein while P2 is produced as a precursor protein (9).

The retained histones may be associated with telomeric sequences and these are the first structures in the sperm nucleus which act as a trigger to oocyte for pronucleus formation to achieve the process of fertilization and early embryo development $(10,11)$.

Protamines are small size proteins contain a lot of positively charged amino acids, especially arginine. This positive charge allows the formation of a highly condensed complex with the paternal genomic DNA, which has a strong negative charge (12).

Protamines size ranging between 4000-12000 Da, are composed of more than $50 \%$ arginine (13). There are 2 types of protamines, namely protamine 1 (P1) and protamine $2(\mathrm{P} 2)$. The incorporation of these 2 proteins into the sperm chromatin is strictly regulated, resulting in specific $\mathrm{P} 1 / \mathrm{P} 2$ ratio (14).

In human sperm, $\mathrm{P} 1 / \mathrm{P} 2$ ratio is approximately 1 in fertile men $(15,16)$. The $\mathrm{P} 1$ of the mammalian placenta is exactly 49 or 50 amino acids long (17). P2 is slightly larger than P1, where contains about 63 amino acids, and is the predominant form of P2 in the mature sperm head. In human sperm, there are 2 differently processed forms of protamine 2; $\mathrm{P} 2$ and $\mathrm{P} 3$. The 2 forms of the $\mathrm{P} 2$ protein differ only in their three amino-terminal amino acids - P3 is 3 amino acids shorter (at 54 amino-acid residues) than P2 (57 amino acids), and they encode by the same gene (PRM2 gene) (17). P2 also differs from $\mathrm{P} 1$ in that $\mathrm{P} 2$ binds zinc, in human and other mammalian species coordinate one zinc atom per molecule of P2 (18).

Disulfide cross-links between the cysteine-rich protamines are responsible for further compaction and stabilization of the sperm nucleus $(19,20)$.

During spermiogenesis, the majority of nucleosomal histones are replaced by protamines in a multi-step process resulting in intensive chromatin (21). First, the somatic histones are replaced by testis-specific histone variants, followed by the replacement of these by transition proteins (transition protein 1 and 2). Finally, transition proteins are replaced by protamines during the spermatid elongation process $(15,16)$.

The deficiency of protamine replacement may not only be a marker of abnormal spermiogenesis, but may also affect the function of the paternal genome contribution during embryogenesis. It may result in suboptimal embryogenesis and/or increased risk of mutations to the offspring (21)

The exact mechanism by which DNA damage arises in human spermatozoa is not clearly understood and three mechanisms have been proposed: defective sperm chromatin packaging, apoptosis, and oxidative stress (22).

\section{Sperm DNA Fragmentation}

Fertilization is the process of penetration of sperm into oocyte. The achievement of this process as well as embryo development depends on the DNA integrity of the sperm (23).

Male infertility has classically been diagnosed by microscopic assessment of concentration, motility and morphology of the sperm in the ejaculate. These tests are essential to provide the basic information of the sperm quality. Sperm DNA fragmentation (SDF) tests can differentiate fertile from infertile males, high levels of SDF are positively correlated with lower fertilization rates in IVF (in vitro fertilization), impaired the implantation rates and an increased abortion incidence (24).

Sperm DNA fragmentation may cause infertility, miscarriage, and birth defects in offspring (25). There are 2 types of factors may cause sperm DNA damage:

1) Intrinsic factors including in the ejaculates such as oxidative stress, apoptosis and failure in the histoneprotamine replacement $(26,27)$. Sperm DNA becomes exposure to damage if chromatin packing is not completed during sperm maturation (24).

DNA fragmentation may also occur during spermiogenesis by endonucleases (topoisomerases), this enzyme act to relieve the increased DNA torsional stress during the DNA condensing and packaging into the differentiating sperm head (28).

2) Extrinsic factors such as storage temperatures, handling conditions, lapse of time after ejaculation, infections, reaction to medicines, or post-testicular oxidative stress (24).

Sperm DNA damage may affect the early post implantation embryo development in ART and thus decrease the fertility and pregnancy rate (29).

Some reports have indicated that when $>30 \%$ of sperm DNA is damaged, natural pregnancy is not possible (30). Also, it has been proposed that the sperm DNA integrity may be a more objective marker of sperm function as opposed to the standard semen analysis (30).

Hofmann and Hilscher (31) mentioned that various nuclear alterations including an abnormal chromatin structure, chromosomes with microdeletions, aneuploidies and DNA strand breaks can be detected in infertile men. Damaged DNA has been observed in testicular, epididymal and ejaculated sperm (24).

DNA repair process occurs in developing sperm but it is terminated as transcription and translation stops post-spermiogenesis. So that mature sperms do not have mechanism to repair DNA abnormality that occurs during their transit and storage in the epididymis or postejaculation. However, ocytes and early embryos have been shown to repair some types of sperm DNA breakage. Consequently, the biological effect of damaged sperm chromatin structure depends on the combined effects of level and type of sperm chromatin damage and the ability of the oocyte to repair it (24).

In mammalian sperms, DNA fragmentations can occur in 2 forms: single (SSB) and double DNA strand breaks 
(DSBs), and it is particularly frequent in the ejaculates of subfertile males (32).

The sperm DNA fragmentation could be induced by oxidative attacks like the hydroxyl radical and ionizing radiation results in the formation of $8-\mathrm{OH}$-guanine and 8-OH-20-deoxyguanosine $(8-\mathrm{OHdG})$ at a first stage and single-stranded DNA fragmentation. Hydroxyl radical formation may result in the indirect induction of doublestranded sperm DNA damage through the activation of sperm caspases and endonucleases (33).

DNA double-strand breaks are extremely harmful lesions that can lead to genomic instability and cell death. There are several possibilities for a cell that is facing DNA damage: despite DNA damage it may be repaired, fertilization of an oocyte by a spermatozoon with doublestranded DNA fragmentation could happen without repairing the DNA and result in abnormal embryo and abnormal fetal development (34).

Genome integrity controlled by means of complicated cellular network. Nevertheless, during initiation of DNA damage by genotoxic stress, series of proteins, in response, are immobilized. There are some proteins complexes act as sensors, transducers and effectors of DNA damage which induced by Double strand breaks DSBs (35). However if un-repaired DSBs persist, cells can undergo apoptosis to prevent the accumulation of potentially tumorigenic mutations. If all the damage responses fail, de novo mutations will appear (36).

\section{Male Genital Tract Infection and Bacteriospermia \\ Male Urogenital Tract Infection}

Male genital tract infection is one of the most important causes of male infertility worldwide. Invasion of bacteria into the male genital tract has been frequently shown to be associated with impaired sperm function, leading to infertility (37). Male urogenital tract infections (UTIs) play an important role in male infertility, being associated with $8 \%-35 \%$ of male infertility. Asymptomatic bacteriospermia play a major role $(37,38)$. A recent study mentioned that UTIs are associated with about $15 \%$ of male infertility (1).

It has been observed that the presence of pathogenic organisms mayinterfere with infertility treatment involving the application of IVF and intra-uterine insemination (39). Pathogenic bacteria such as streptococci, staphylococci, Mycoplasma, Chlamydia and Ureaplasma produce an acute inflammatory response with a flow of leucocytes into the genital tract leading to increase the level of reactive oxygen species (ROS) production (29,40-42). Excessive like these substances have negative effects on sperm parameters (43). Hammadeh et al (44) reported that the increase of ROS concentration in seminal plasma has negative effects on sperm vitality, membrane integrity, sperm density, chromatin condensation, and DNA single stand breaks.

Cunningham and Beagley (45) referred to some pathogenic bacterial species that well-known as causative pathogens of genitourinary infections and can interact with spermatozoa such as Escherichia coli, Ureaplasma urealyticum, Mycoplasma hominis and Chlamydia trachomatis. Mehta et al (46) isolated some pathogenic bacteria from semen samples of male partners in infertile couples, including Enterococcus faecalis, micrococci, and alpha-haemolytic streptococci. Other studies mentioned that the contamination and colonization of some bacteria in the male urogenital tract, rather than infection, could also contribute to the decrease in sperm quality $(47,48)$.

\section{Asymptomatic Bacteriospermia}

Asymptomatic bacteriospermia (ABS) is an invisible infection in the male genital tract and considered as a major cause of male infertility (49).

The passive or active invasion of these bacterial strains induce a generalized or local reaction in the urogenital tract and is often observed as an asymptomatic subclinical inflammation caused by pathogens $(50,51)$.

Khalili and Sharifi-Yazdi (52) isolated different bacterial species from $34.4 \%$ of semen samples, like Streptococci pyogenes, Enetrococci, E. coli and staphylococci. These bacteria had negative effects on the morphology and the motility of sperms.

Fraczek et al (53) concluded that the incubation of sperm with bacteria and/or leukocytes was associated with reduction of their fertilization potentials resulting in the negative impact of bacteria and white blood cells (WBCs) on the sperm motility and sperm membrane lipid bilayers.

In Iran, Golshani et al (49) found that $35.22 \%$ of infertile men showed at least 1 pathogen. E. coli, Coagulase-negative staphylococci (saprophyticus), group B streptococci, 5.88\% enterococci, Candida sp., gonococci, Staphylococcus aureus, Klebsiella sp. and Providencia sp. were isolated. Also, there was a significant $(P<0.001)$ positive relation between the bacteriospermia and immotile sperm rat and abnormality of sperm morphology.

\section{Leukocytospermia}

A high concentration of WBCs $\left(\geq 1 \times 10^{6} / \mathrm{mL}\right)$ in semen samples is a marker of microbial inflammation (54). Male accessory gland infections which produced leukocytes was a condition frequently detected in infertile patients $(55,56)$. Leukocytes appear in semen as the addition to bacteriospermia at the second stage of the UTI, and remain present in semen for some period of time following the elimination of the bacteria in the third stage (1).

In vitro studies have shown significant positive correlations between WBCs in semen and deterioration in total sperm count $(50)$, motility $(53,57)$, morphology $(50,57,58)$ and sperm viability $(57)$.

Many authors have concluded that the leukocytospermia has a negative impact on semen quality due to the production of reactive oxygen species (ROS) (59-61). The ROS produced by leukocytes increase the apoptosis in mature human spermatozoa (29). Other authors reported that semen samples with leukocytospermia are more likely to evidence sperm with DNA fragmentation $(58,62)$. 
On the other hand, some investigators reported that the final effects of the cells of the immune system on spermatozoa may depend on their activity, regardless of the number of leukocytes in the semen (63-65). However, Golshani (49) mentioned that the presence of bacteriospermia and leukocytospermia did not correlate with each other. It seems that leukocytospermia is a poor marker to predict bacteriospermia.

The Effects of Bacterial Infection on Sperm Parameters The presence of bacteria might alter the sperm quality (48).

Microbial infections have been reported to reduce sperm viability (66). Microorganisms might affect the male reproductive function in different ways:

1) Some pathogenic bacterial strains present in semen may act directly on sperm cells causing the agglutination of motile sperm, reducing the ability for the acrosome reaction, and also causing alterations in cell morphology (67). For example E. coli strains are known for their ability to immobilize and damage the morphology of spermatozoa by direct contact, mediated by attachment organelles such as pili or type-1 fimbriae (projections) and mannose receptor-dependent interactions (68). Also, the sperm surface is rich in glycoproteins and is therefore susceptible to the nitration of bacteria such as E. coli, C. trachomatis, U. urealyticum, Staphylococcus haemolyticus and Bacteroides ureolyticus with spermatozoa leading to the loss of sperm motility and normal morphology (1).

Some researchers were isolated the spermagglutination factor from $S$. aureus, which showed spermagglutinating and spermicidal properties in vitro (69).

2) Microorganisms trigger a local inflammatory reaction. The inflammatory response of the genitourinary tract to the invasion of microorganisms and inflammation is considered to be extremely similar to the reaction observed in other sites of the body (70). This physiological response activates leukocytes and inflammatory mediators such as cytokines and reactiveoxygen species (ROS) which are known to play important roles in sperm DNA fragmentation and male infertility (67). The inflammatory process caused by pathogenic bacteria in the genital tract may lead to a deterioration of spermatogenesis and obstruction of the seminal tract (71). The induction all of the inflammatory reactions in the seminal tract through the activation of neutrophils and macrophages may indirectly exert a deleterious effect on male fertility, where most of the leukocytes attracted to the semen during bacterial semen infection are phagocytic cells such as polymorphonuclear granulocytes (PMNs) and macrophages. The tight adhesion of neutrophils, and macrophages to the surface of the sperm results in phagocytic process (1) (Figure 1). The sperm abnormal form associated with elongation and reduced acrosomal inducibility have been found in men with inflammatory chronic prostatitis and these changes were attributed to leukocytes (72).

3) Induction of sperm autoantibodies (73).

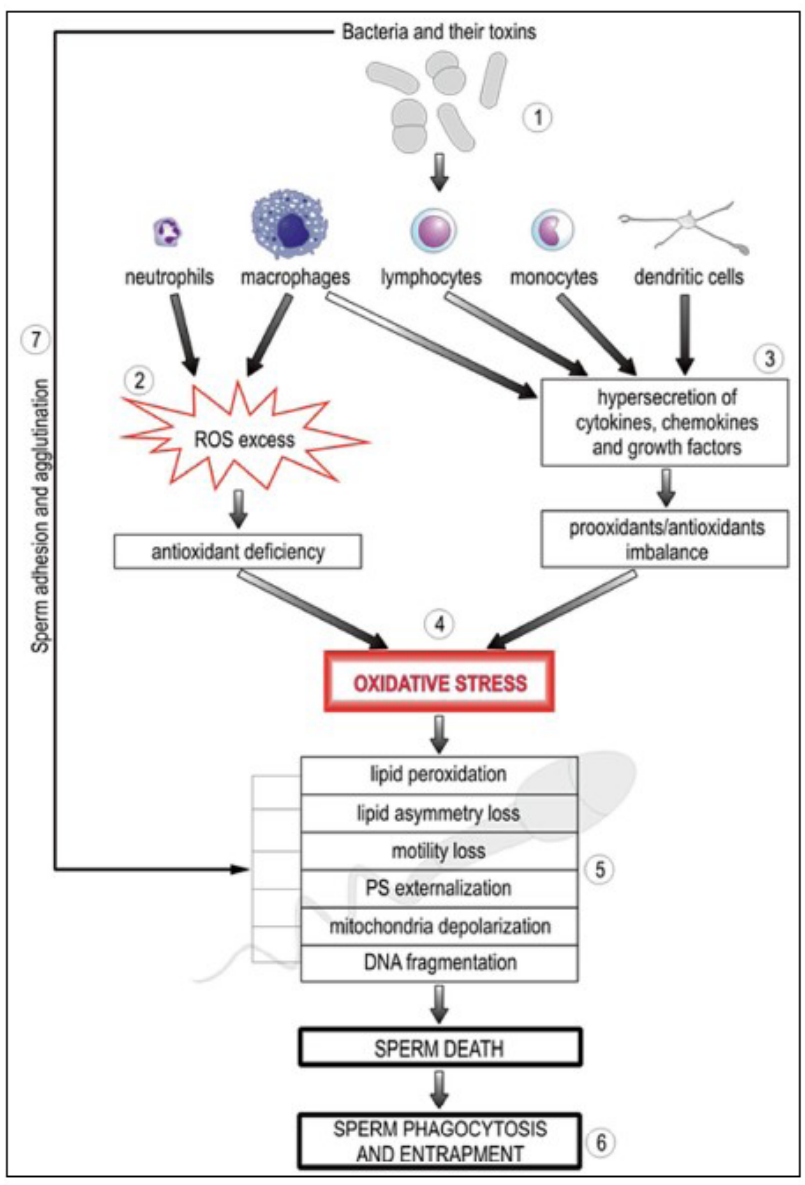

Figure 1. Mechanisms of the Negatively Effect of Bacteriospermia on Human Spermatozoa. (1) Bacteria and their toxins trigger the infiltration of immune cells connected with (2) the production and release of ROS by neutrophils and macrophages as well as (3) immune regulatory factors; cytokines, chemokines and growth factors from macrophages, lymphocytes, monocytes, and dendritic cells leading to (4) oxidative stress (5) oxidative stress induces lipid sperm membrane peroxidation and leads to decrease sperm fertility potentials and thus sperm DNA fragmentation and sperm death. (6) Damaged and dead spermatozoa can occur by traditional phagocytosis; or by (7) direct adhering of bacteria to spermatozoa. Adapted from Fraczek and Kurpisz (1).

4) Some microbial pathogens may affect the sperm, resulting in the expression of some surface virulent factors such as lipopolysaccharides (LPS), cytotoxic necrotising factor, $\alpha$-haemolysins and $ß$-haemolysins, and from the release of soluble spermatotoxic factors such as sperm immobilisation factor (SIF) $(74,75)$.

A single incubation with E. faecalis, E. coli and $S$. aureus induced apoptosis in human sperm with two possible, putative mechanisms: a direct cytotoxic activity of bacterial toxins and the contact with pili and flagella. It has also been demonstrated that E. coli can start the apoptotic process by activating several caspases, proteases responsible for mitochondrial changes, alterations in membrane symmetry, and DNA fragmentation (48).

Other study revealed that the $E$. coli showed a significant increase in apoptosis in sperm, and the bacterial infection 
of male genital tract decrease the motility and increase in non-viable sperm, as well as causing sperm DNA fragmentation (29).

Escherichia is the most extensively studied microorganism in relation to infertility as a result of interaction with spermatozoa (76). It is also the primary bacteria associated with prostatitis and epididymitis (77). E. coli has a passive effect on sperm motility and acrosomal function (48). Several authors were described spermagglutination and immobilization by E. coli $(52,78)$.

In rats, infection with uropathogenic E. coli (UPEC) results in severely impaired spermatogenesis, characterized by, for example hypospermatogenesis, germ cell loss and reduced sperm number (79). Kaur and Prabha (69) isolated Sperm agglutination factor from $S$. aureus which showed sperm agglutinating and spermicidal properties in vitro.

In human, E. coli and $S$. aureus are the predominant flora in infertile men (80). Other authors reported that these species of bacteria can cause a significant decrease in sperm motility (81). Emokpae et al (82) studied the contribution of seminal tract infection to sperm density, asthenozoospermia and teratozoospermia, where they observed $S$. aureus as the causative organism accounting for $68.2 \%$ of seminal infections. S. aureus is known to produce various toxins and enzymes that may exert a damaging effect on human sperm.

The increased prevalence of genital tract infections caused by E. faecalis is associated with a deterioration of semen quality in terms of sperm concentration and morphology. Also the presence of micrococci and alphahaemolytic streptococci does not appear to exert any detrimental effect on sperm quality (46).

Although no significant depressor effect of enterococci on sperm motility was observed (48), some researchers described, in an in vitro study, a negative influence on membrane integrity of human sperm head, neck and mid-piece (83), probably mediated by haemolysin, a wellknown virulence factor of enterococci.

5) Infection treatment with antibiotics

In spite of the sperm parameters being improved after the treatment of UTIs (84), antibiotics have negative effects on sperm motility and morphology (67).

\section{The Effects of Bacterial Infection on Sperm Chromatin Condensation and DNA Integrity}

Different bacterial species such as $S$. aureus, E. coli, $P$. aeruginosa can cause sperm DNA fragmentation (29). The effect of the male genital tract infection depends on the pathogen type, acute or chronic condition as well as the site of infection, where the inflammation can occur in the epididymis, prostate gland or seminal vesicles (66). In certain situation the genital tract inflammation become difficult to diagnose because the symptoms may not be apparent (Asymptomatic infection) and the patients only suffering from some local discomfort (85).

Human patients infected with $C$. trachomatis and Mycoplasma had a significant $(P<0.05)$ increased of sperm DNA damage compared to control individuals (86). This effect has also been seen in other animal species (87). However, Rybar et al concluded that the contaminated semen with C. trachomatis, Ureaplasma and Mycoplasma spp. were not associated with sperm DNA fragmentation (85).

The exact molecular mechanism of how bacteria infections affect chromatin and sperm nuclear protein still unknown. In mammals, postmeiotic spermatogenesis is characterized by a dramatic reorganization and compaction of the chromatin. The nucleosomal histonebased structure is largely replaced by a transition proteinbased structure and eventually by a protamine-based structure (88-91).

Dottermusch-Heidel et al (92) reported that the bacterial infections lead to the premature emergence of trimethylated $\mathrm{H} 3 \mathrm{~K} 79$ and hyperacetylated $\mathrm{H} 4$, which simultaneously occur with the transition protein TNP1. In contrast, they were never observed in the spermatids of infected rats. Furthermore, upon bacterial infection, only histone-based spermatid chromatin showed abnormalities; whereas protamine compacted chromatin seemed to be unaffected.

Hyperacetylation of histone $\mathrm{H} 4$ occurs during the histone-to-protamine transition, perhaps causing a more open chromatin structure to facilitate histone replacement (93-96) and serving as a signal for the bromodomain protein BRDT to initiate the histone-to-protamine transition (97). In mammals, reduced levels of histone H4 hyperacetylation correlates with impaired fertility $(95,98)$.

Many researchers found that there are different bacteria species can affect sperm DNA integrity for examples: $S$. aureus, E. coli, Pseudomonas aeruginosa, C. trachomatis, U. urealyticum, Mycoplasma spp. and C. albicans. They can induce the expression of apoptosis in the male genital tract during inflammatory processes (68).

The increased sperm DNA fragmentation in an infertile patient with the male accessory gland infection is due to influence of reactive oxygen species produced by activated leukocytes at the level of apoptosis in mature human spermatozoa, E. coli showed significant increase in apoptosis on spermatozoa as will as cause alteration of human sperms (29).

Gallegos et al (86) demonstrated that human patients infected with C. trachomatis and Mycoplasma have increased values of sperm DNA damage compared to control individuals.

Burrello et al (99) reported that the male accessory gland infection with C. albicans increased sperm DNA fragmentation and sperm chromatin packaging damage.

\section{Pathogenicity of Some Bacterial Species on Sperm}

Some gram-negative Enterobacteriaceae such as E. coli, Klebsiella spp., Proteus, Serratia, Pseudomonas spp., etc are considered pathogens for the urogenital system (100). The major difficulty in interpreting microbiological findings is the presence of contaminating, indigenous microbiota, or of inhibitory substances known to be present in 
the prostate secretions, as well as previous courses of antibiotics (77). The diagnosis of semen bacterial infection may be confirmed by semen quantitative bacteriological cultures. The semen cultures were considered positive when the number of bacteria colonies was $>10^{3} \mathrm{CFU} / \mathrm{mL}$, according to Domes et al (58).

Several of the bacterial species have negative effects on sperm conventional parameters, chromatin condensation and DNA integrity (100). In the experimental infection module, the incubation of human sperm with suspensions of some bacterial species such as E. coli, S. haemolyticus, and $B$. ureolyticus resulted in a reduction of sperm motility (53).

\section{Staphylococcus aureus}

Staphylococcus aureus is one of the most pathogenic bacteria as it can infect various organs in the body (101). Various studies revealed that S. aureus was the most common isolated bacterial species from seminal fluid samples. Prabha et al (102) found that $51.85 \%$ of seminal fluid samples were contaminated with $S$. aureus. Additionally, Emokpae et al (82) detected S. aureus in $68.2 \%$ of the seminal fluid. Contamination of seminal fluid with $S$. aureus significantly increased the risk of recurrent pregnancy abortion (103). S. aureus produces a protein molecule (MW $=20 \mathrm{kDa})$ called SIF. It was isolated and purified by Prabha et al (104), where they reported that SIF can lead to complete immobilization of spermatozoa at a concentration of $150 \mathrm{mg} / \mathrm{ml}$; whereas $200 \mathrm{mg} / \mathrm{mL}$ of this factor is required to kill spermatozoa.

\section{Escherichia coli}

There were several investigations that have described the harmful effects of $E$. coli on sperm fertilization potentials. Fraczek et al (53) concluded that E. coli and serotype O75:HNT have a negative effect on human sperm motility. An inhibitory effect of E. coli, serotype 06, on sperm motility has been investigated by some authors (105). Sperm incubated with E. coli demonstrated significant alterations in motility $(78,106)$. Some investigators revealed that the immobilization of spermatozoa may occur as a result of direct contact of the sperm with bacterial cells $(105,107)$.

Villegas et al (68) concluded that the direct exposure of spermatozoa to E. coli is enough to decrease sperm quality. They noticed that the early apoptosis incident (phosphatidyl serine [PS] externalization) was significantly increased in spermatozoa after incubation with E. coli alone. Other in vitro studies demonstrated that the soluble products of $E$. coli decreased sperm motility by causing defects in the sperm's mitochondrial function $(108,109)$. SIF was isolated from E. coli by Prabha et al (110), where they reported that the incubation of spermatozoa with SIF causes sperm immobilization and structural modification.

Escherichia coli have certain virulence characteristics and have the ability to adhere to sperm cells and to colonize tissues of the male genital tract, thereby causing asymptomatic male infertility (76).

\section{Neisseria gonorrhoeae}

Neisseria gonorrhoeae is diplococcus bacteria, which infect men and women alike, causing gonorrhea (111). The seminal fluid acts as a mediator triggering the motility of N. gonorrhoeae and microcolony formation via an increase in the number of pili on the bacterial surface (112). N. gonorrhoeae may attach to the spermatozoa by pili as $\mathrm{T} 1$ gonococci or by direct contact as $\mathrm{T} 4$ gonococci (113). Gonococcal infection caused by N. gonorrhoeae triggers the flow of PMNs into the infected tissue (114). As mentioned previously, the presence of leucocytes in the genital tract can increase the level of reactive oxygen species which have harmful effects on spermatozoa $(40,42)$. On the contrary, Liu et al (115), did not find any effects on the sperm by $N$. gonorrhoeae after in vitro incubation.

\section{Ureaplasma urealyticum}

Ureaplasma urealyticum is a common bacteria present in the genitourinary tract and it is more prevalent in infertile men, where it has the ability to affect the sperm morphology (116). Various authors noted that there was a significant correlation between lower sperm concentration and the presence of $U$. urealyticum in the male genital tract (100). Furthermore, one study revealed that infected patients with $U$. urealyticum showed a significant impairment of sperm concentration, motility, and vitality. The authors found that the seminal plasma alpha-glucosidase decreased in the infected patients when compared with in the non-infected patients (117). Kohn el al (118) studied the effect of U. urealyticum on human sperm. It was noticed that $69 \%$ of infected patients with $U$. urealyticum had a decreased capacity of sperm acrosome reaction.

\section{Chlamydia trachomatis}

Chlamydial infection is a popular sexually transmitted disease that is caused by $C$. trachomatis. It affects approximately 90 million people yearly worldwide (51). C. trachomatis infection has a positive correlation with apoptosis rate in the human spermatozoa (119). Furthermore, Gallegos et al (86) demonstrated the negative effect of chlamydial infection on the sperm DNA.

Kokab et al (51) found a significant relationship between chlamydial infections and an increase the level of IL-8 and seminal leukocytes. While the progressively motile sperm decreased in infected patients with C. trachomatis, another bacterial species had a negative effect on sperm parameters. E. faecalis, for instance, had negative effects on sperm motility and morphology (46). The results of another study clearly showed a spermicidal activity of Streptococcus anginosus, thereby, affecting sperm concentration and triggering necrosis. Additionally, Staphylococcus epidermidis had negative effects on sperm concentration and progressive motility (48).

In an in vitro study, the incubation of spermatozoa with Mycoplasma hominis reduced sperm motility and acrosome reaction property (118). Moreover, Mycoplasma 
had a negative effect on sperm DNA integrity (86). The positive correlation between Klebsiella spp. infection and morphologically abnormal spermatozoa were also reported (120).

\section{Conclusion}

The bacteria in semen samples have negative effects on sperm parameters and may be an important factor negatively influencing fertility status and worsening reproductive potential (53).

The molecular mechanism of how bacteria affect chromatin and sperm nuclear protein still unknown exactly. The bacterial infection should be treated with care, especially in patients consulting for infertility and advising for assisted reproduction techniques.

\section{Ethical Issues}

Not Applicable.

\section{Conflict of Interests}

The authors declare no conflicts of interests.

\section{Financial Support}

This study received no funding.

\section{Acknowledgments}

I am grateful to thank, Dr. Majed Alhudhud, Consultant Obstetrician and Gynaecologist, UK for revising the text language.

\section{References}

1. Fraczek M, Kurpisz M. Mechanisms of the harmful effects of bacterial semen infection on ejaculated human spermatozoa: potential inflammatory markers in semen. Folia Histochem Cytobiol. 2015;53(3):201-217. doi:10.5603/fhc.a2015.0019.

2. Bray JJ, Cragg PA, Mac Knight AD, Mills RG. Human physiology. 4th ed. UK: Cambridge University Press; 1999:610.

3. Ehmcke J, Wistuba J, Schlatt S. Spermatogonial stem cells: questions, models and perspectives. Hum Reprod Update. 2006;12(3):275-282. doi:10.1093/humupd/dmk001.

4. Guyton AC. Human physiology and mechanisms of diseases. 5th ed. W.B. Saunders Publishers;1992:690.

5. World Health Organization. WHO Laboratory Manual for the Examination and Processing of Human Semen. 5th ed. Cambridge, UK: Cambridge University Press; 2010.

6. Manicardi GC, Tombacco A, Bizzaro D, Bianchi U, Bianchi P, Sakkas D. DNA strand breaks in ejaculated human spermatozoa: comparison of susceptibility to the nick translation and terminal transferase assays. Histochem J. 1998;30(1):33-39.

7. Gatewood JM, Cook GR, Balhorn R, Bradbury EM, Schmid CW. Sequence-specific packaging of DNA in human sperm chromatin. Science. 1987;236(4804):962-964.

8. Conwell CC, Vilfan ID, Hud NV. Controlling the size of nanoscale toroidal DNA condensates with static curvature and ionic strength. Proc Natl Acad Sci U S A. 2003;100(16):9296-9301. doi:10.1073/pnas.1533135100.

9. Torregrosa N, Domínguez-Fandos1 D, Camejo MI, et al. Protamine 2 precursors, protamine 1/protamine 2 ratio, DNA integrity and other sperm parameters in infertile patients.
Human Reprod. 2006;21(8):2084-2089. doi:10.1093/ humrep/del114.

10. Gineitis AA, Zalenskaya IA, Yau PM, Bradbury EM, Zalensky AO. Human sperm telomere-binding complex involves histone $\mathrm{H} 2 \mathrm{~B}$ and secures telomere membrane attachment. J Cell Biol. 2000;151(7):1591-1598.

11. Zalenskaya IA, Bradbury EM, Zalensky AO. Chromatin structure of telomere domain in human sperm. Biochem Biophys Res Commun. 2000;279(1):213-218. doi:10.1006/ bbrc.2000.3917.

12. Wouters-Tyrou D, Martinage A, Chevaillier P, Sautiere P. Nuclear basic proteins in spermiogenesis. Biochimie. 1998;80(2):117-128.

13. Lewis JD, Song Y, de Jong ME, Bagha SM, Ausio J. A walk though vertebrate and invertebrate protamines. Chromosoma. 2003;111(8):473-482. doi:10.1007/s00412002-0226-0.

14. Corzett M, Mazrimas J, Balhorn R. Protamine 1: protamine 2 stoichiometry in the sperm of eutherian mammals. Mol Reprod Dev. 2002; 61(4):519-527. doi:10.1002/mrd.10105.

15. Oliva R. Protamines and male infertility. Hum Reprod Update. 2006;12(4):417-435. doi:10.1093/humupd/dml009.

16. Carrell DT, Emery BR, Hammoud S. Altered protamine expression and diminished spermatogenesis. Hum Reprod. 2007;13(3):313-327. doi:10.1093/humupd/dml057.

17. Balhorn R. The protamine family of sperm nuclear proteins. Genome Biology. 2007;8(9):227. doi:10.1186/gb-2007-8-9227.

18. Bench GS, Corzett MH, Kramer CE, Grant PG, Balhorn R. Zinc is sufficiently abundant within mammalian sperm nuclei to bind stoichiometrically with protamine 2. Mol Reprod Devel. 2000;56(4):512-519. doi:10.1002/10982795(200008)56:4<512::AID-MRD9>3.0.CO;2-M.

19. Rufas O, Fisch B, Seligman J, Tadir Y, Ovadia J, Shalgi R. Thiol status in human sperm. Mol Reprod Dev. 1991;29(3):282288. doi:10.1002/mrd.1080290311.

20. Kosower NS, Katayose H, Yanagimachi R. Thioldisulfide status and acridine orange fluorescence of mammalian sperm nuclei. J Androl. 1992;13(4):342-348. doi:10.1002/j.1939-4640.1992.tb00335.

21. Nanassy L, Liu L, Griffin J, Carrell DT. The clinical utility of the protamine 1/protamine 2 ratio in sperm. Protein Pept Lett. 2011;18(8):772-7. doi:10.2174/092986611795713934.

22. Agarwal A, Said TM. Sperm Chromatin Assessment. In: Gardner DK, Weissman A, Howles CM, Shoham Z, eds. Textbook of Assisted Reproductive Techniques. 3rd ed. London, UK; 2009:67-84.

23. Ahmadi A. Fertilizing ability of DNA-damaged spermatozoa. J Exp Zool. 1999;284(6):696-704.

24. González-Marín C, Gosálvez J, Roy R. Types, causes, detection and repair of DNA fragmentation in animal and human sperm cells. Int J Mol Sci. 2012;13(11):14026-14052. doi:10.3390/ijms131114026.

25. Aitken RJ, De Iuliis GN. On the possible origins of DNA damage in human spermatozoa. Mol Hum Reprod. 2010;16(1):3-13. doi:10.1093/molehr/gap059.

26. Agarwal A, Makker K, Sharma R. Clinical relevance of oxidative stress in male factor infertility: an update. Am J Reprod Immunol. 2008;59(1):2-11. doi:10.1111 /j.1600-0897.2007.00559.

27. Sakkas D, Mariethoz E, Manicardi G, Bizzaro D, Bianchi PG. Origin of DNA damage in ejaculated human spermatozoa. Rev.Reprod. 1999;4(1):31-37.

28. Marcon L, Boissonneault G. Transient DNA strand 
breaks during mouse and human spermiogenesis new insights in stage specificity and link to chromatin remodeling. Biol Reprod. 2004;70(4):910-918. doi:10.1095/ biolreprod.103.022541.

29. Sasikumar S, Dakshayani D, Sarasa D. An investigation of DNA fragmentation and morphological changes caused by bacteria and fungi in human spermatozoa. Int J Curr Microbiol App Sci. 2013;2(4):84-96.

30. Evenson DP, Larson KL, Jost LK. Sperm chromatin structure assay: its clinical use for detecting sperm DNA fragmentation in male infertility and comparisons with the other techniques. J Androl. 2002;23(1):25-43. doi:10.1002/j.1939-4640.2002. tb02599.

31. Hofmann N, Hilscher B. Use of aniline blue to assess chromatin condensation in morphologically normal spermatozoa in normal and infertile men. Hum Reprod. 1991;6(7):979-982.

32. Enciso M, Sarasa J, Agarwal A, Fernández JL, Gosálvez J. A two-tailed Comet assay for assessing DNA damage in spermatozoa. Reprod Biomed Online. 2009;18(5):609-616.

33. Badouard C, Ménézo Y, Panteix G, et al. Determination of new types of DNA lesions in human sperm. Zygote. 2008;16(1):9-13. doi:10.1017/S0967199407004340.

34. Garcia-Diaz M, Dominguez O, Lopez-Fernandez LA, et al. DNA polymerase lambda (Pol lambda), a novel eukaryotic DNA polymerase with a potential role in meiosis. J Mol Biol. 2000;301(4):851-867. doi:10.1006/jmbi.2000.4005.

35. Polo SE, Jackson SP. Dynamics of DNA damage response proteins at DNA breaks: A focus on protein modifications. Genes Dev. 2011;25(5):409-433. doi:10.1101/gad.2021311.

36. Wang J, Fan HC, Behr B, Quake SR. Genome-wide single-cell analysis of recombination activity and de novo mutation rates in human sperm. Cell. 2012;150(2):402-412. doi:10.1016/j. cell.2012.06.030.

37. Askienazy-Elbhar M. Male genital tract infection: the point of view of the bacteriologist. Gynecol Obstet Fertil. 2005;33(9):691-697. doi:10.1016/j.gyobfe.2005.07.008.

38. Kopa Z, Wenzel J, Papp GK, Haidl G. Role of granulocyte elastase and interleukin- 6 in the diagnosis of male genital tract inflammation. Andrologia. 2005;37(5):188-194. doi:10 $.1111 / j .1439-0272.2005 .00676$.

39. Damirayakhain M, Jeyendran RS, Land SA. Significance of semen cultures for men with questionable semen quality. Arch Androl. 2006;52(4):239-242. doi:10.1080/01485010600630132.

40. Ochsendorf FR. Infections in the male genital tract and reactive oxygen species. Hum Reprod Update. 1999;5(5):399420. doi:10.1093/humupd/5.5.399.

41. Pasqualotto FF, Sharma RK, Potts JM, Nelson, DR, Thomas AJ, Agarwal A. Seminal oxidative stress in patients with chronic prostatitis. Urology. 2000;55(6):881-885. doi:10.1016/S0090-4295(99)00613-5.

42. Potts RJ, Notarianni LJ, Jefferies TM. Seminal plasma reduces exogenous oxidative damage to human sperm, determined by the measurement of DNA strand breaks and lipid peroxidation. Mutat Res. 2000;447(2):249-256. doi:10.1016/ S0027-5107(99)00215-8.

43. Segnini A, Camejo MI, Proverbio F. Chlamydia trachomatis and sperm lipid peroxidation in infertile men. Asian J Androl. 2003;5(1):47-49.

44. Hammadeh ME, Al Hasani S, Rosenbaum P, Schmidt W, Fischer Hammadeh C. Reactive oxygen species, total antioxidant concentration of seminal plasma and their effect on sperm parameters and outcome of IVF/ICSI patients.
Arch Gynecol Obstet. 2008;277(6):515-526. doi:10.1007/ s00404-007-0507-1.

45. Cunningham KA, Beagley KW. Male genital tract chlamydial infection: implications for pathology and infertility. Biol Reprod. 2008;79(2):180-189. doi:10.1095/ biolreprod.108.067835.

46. Mehta RH, Sridhar H, Vijay Kumar BR, Anand Kumar TC. High incidence of oligozoospermia and teratozoospermia in human semen infected with the aerobic bacterium Streptococcus faecalis. RBM Online. 2002;5(1):17-21. doi:10.1016/S1472-6483(10)61591-X.

47. Cottell E, Harrison RF, McCaffrey M, Walsh T, Mallon E, Barry-Kinsella C. Are seminal fluid microorganisms of significance or merely contaminants? Fertil Steril. 2000;74(3):465-470. doi:10.1016/S0015-0282(00)00709-3.

48. Moretti E, Capitani S, Figura N, et al. The presence of bacteria species in semen and sperm quality. J Assist Reprod Genet. 2009;26(1):47-56. doi:10.1007/s10815-008-9283-5.

49. Golshani M, Taheri S, Eslami G, Suleimani Rahbar AA, Fallah F, Goudarzi H. Genital tract infection in asymptomatic infertile men and its effect on semen quality. Iran J Public Health. 2006;35(3):81-84.

50. Bezold G, Politch JA, Kiviat NB, Kuypers JM, Wolff H, Anderson DJ. Prevalence of sexually transmissible pathogens in semen from asymptomatic male infertility patients with and without leukocytospermia. Fertil Steril. 2007;87(5):10871097. doi:10.1016/j.fertnstert.2006.08.109.

51. Kokab A, Akhondi MM, Sadeghi MR, et al. Raised inflammatory markers in semen from men with asymptomatic chlamydial infection. J Androl. 2010;31(2):114-120. doi:10.2164/jandrol.109.008300.

52. Khalili MB, Sharifi-Yazdi MK. The effect of bacterial infection on the quality of human's spermatozoa. Iran J Public Health. 2001;30(3-4):119-122.

53. Fraczek M, Wiland E, Piasecka M, et al. Fertilizing potential of ejaculated human spermatozoa during in vitro semen bacterial infection. Fertil Steril. 2014;102(3):711-719. doi:10.1016/j.fertnstert.2014.06.002.

54. World Health Organization. Laboratory manual for the examination of human semen and sperm-cervical mucus interaction. 4th ed. edn. Cambridge, UK: Cambridge University Press; 1999.

55. Arata de Bellabarba G, Tortolero I, Villarroel V, Molina CZ, Bellabarba C, Velazquez E. Nonsperm cells in human semen and their relationship with semen parameters. Arch Androl. 2000;45(3):131-136.

56. Kaleli S, Ocer F, Irez T, Budak E, Aksu MF. Does leukocytospermia associate with poor semen parameters and sperm functions in male infertility? The role of different seminal leukocyte concentrations. Eur J Obstet Gynecol Reprod Biol. 2000;89(2):185-191.

57. Moretti E, Collodel G, Mazzi L, Campagna M, Iacoponi F, Figura N. Resistin, interleukin-6, tumor necrosis factoralpha, and human semen parameters in the presence of leukocytospermia, smoking habit, and varicocele. Fertil Steril. 2014;102(2):354-360. doi:10.1016/j.fertnstert.2014.04.017.

58. Domes T, Lo KC, Grober ED, Mullen JBM, Mazzulli T, Jarvi $\mathrm{K}$. The incidence and effect of bacteriospermia and elevated seminal leukocytes on semen parameters. Fertil Steril. 2012;97(5):1050-1055. doi:10.1016/j.fertnstert.2012.01.124.

59. Henkel R, Ichikawa T, Sanchez R, Miska W, Ohmori H, Schill WB. Differentiation of ejaculates showing reactive oxygen species production by spermatozoa or leukocytes. Andrologia. 1997;29(6):295-301. doi:10.1111/j.1439-0272.1997.tb00322. 
60. Saleh RA, Agarwal A, Kandirali E, et al. Leukocytospermia is associated with increased reactive oxygen species production by human spermatozoa. Fertil Steril. 2002;78(6):1215-1224. doi:10.1016/S0015-0282(02)04237-1.

61. Lemkecher T, Dartigues S, Vaysse J, et al. Leucocytospermia, oxidative stress and male fertility: facts and hypotheses. Gynecol Obstet Fertil. 2005;33(1-2):2-10. doi:10.1016/j. gyobfe.2005.01.001.

62. Fariello RM, Del Giudice PT, Spaine DM, Fraietta R, Bertolla RP, Cedenho AP. Effect of leukocytospermia and processing by discontinuous density gradient on sperm nuclear DNA fragmentation and mitochondrial activity. J Assist Reprod Genet. 2009;26(2-3):151-157. doi:10.1007/s10815-008-92880 .

63. Weidner W, Pilatz A, Diemer T, Schuppe HC, Rusz A, Wagenlehner F. Male urogenital infections: impact of infection and inflammation on ejaculate parameters. World J Urol. 2013;31(4):717-723. doi:10.1007/s00345-013-1082-7.

64. Fraczek M, Kurpisz M. Inflammatory mediators exert toxic effects of oxidative stress on human spermatozoa. J Androl. 2007; 28(2):325-333. doi:10.2164/jandrol.106.001149.

65. Aitken RJ, Baker MA. Oxidative stress, spermatozoa and leukocytic infiltration: relationships forged by the opposing forces of microbial invasion and the search for perfection. J Reprod Immunol. 2013;100(1):11-19. doi:10.1016/j. jri.2013.06.005.

66. Wolff HG. The biologic significance of white blood cells in semen. Fertil Steril. 1995;63(6):1143-1157.

67. Sanocka D, Fraczek M, Jedrzejczak P, Szumała-Kakol A, Kurpisz M. Male genital tract infection: an influence of leukocytes and bacteria on semen. Reprod Immun. 2004;62(1-2):111-124. doi:10.1016/j.jri.2003.10.005.

68. Villegas J, Schulz M, Soto L, Sanchez R. Bacteria induce expression of apoptosis in human spermatozoa. Apoptosis. 2005;10(1):105-110. doi:10.1007/s10495-005-6065-8.

69. Kaur S, Prabha V. Characterization of sperm agglutinating factor isolated from Staphylococcus aureus and its corresponding receptor from spermatozoa. Adv Stud Med Sci. 2013;1(2):61-68.

70. Zorn B, Sesek-Briski A, Osredkar J, Meden-Vrtovec H. Semen polymorphonuclear neutrophil leukocyte elastase as a diagnostic and prognostic marker of genital tract inflammation--a review. Clin. Chem. Lab Med. 2003;41(1):212. doi:10.1515/CCLM.2003.002.

71. Keck C, Gerber-Schafer C, Clad A, Wilhelm C, Breckwoldt M. Seminal tract infections: impact on male fertility and treatment options. Hum Reprod. 1998;4(6):891-903. doi:10.1093/humupd/4.6.891.

72. Menkveld R, Huwe P, Ludwig M, Weidner W. Morphological sperm alternations in different types of prostatitis. Andrologia. 2003;35(5):288-293. doi:10.1046/j.1439-0272.2003.00574.

73. Purvis K, Christiansen E. Infection in the male reproductive tract. Impact, diagnosis and treatment in relation to male infertility. Int J Androl. 1993;16(1):1-13. doi:10.1111/j.1365-2605.1993.tb01146.

74. Agarwal J, Srivastava S, Singh M. Pathogenomics of uropathogenic Escherichia coli. Indian J Med Microbiol. 2012;30(2):141-149. doi:10.4103/0255-0857.96657.

75. Prabha V, Chaudhary N, Kaur S. Molecular mimicry between spermatozoa and bacteria. J Urol. 2011;186(6):2442-2447. doi:10.1016/j.juro.2011.07.084.

76. Bartoov B, Ozbonfil D, Maayan MC, Ohad E, Nitzan Y. Virulence characteristics of male genital tract Escherichia coli isolated from semen of suspected infertile men. Andrologia.
1991;23(5):387-94. doi:10.1111/j.1439-0272.1991.tb02586.

77. Comhaire F, Verschraegen G, Vermeulen L. Diagnosis of accessory gland infection and its possible role in male infertility. Int $J$ Androl. 1980;3(1):32-45. doi:10.1111/j.1365-2605.1980.tb00093.

78. Huwe P, Diemer T, Ludwig M, Liu J, Schiefer HG, Weidner W. Influence of different uropathogenic microorganisms on human sperm motility parameters in an in vitro experiment. Andrologia. 1998;30(S1):55-59. doi:10.1111/j.1439-0272.1998.tb02827.

79. Lu Y, Bhushan S, Tchatalbachev S, et al. Necrosis is the dominant cell death pathway in uropathogenic Escherichia coli elicited epididymo-orchitis and is responsible for damage of rat testis. PLoS One. 2013;8(1):e52919. doi:10.1371/ journal.pone.0052919.

80. Momoh AR, Idonije BO, Nwoke EO, et al. Pathogenic bacteria-a probable cause of primary infertility among couples in Ekpoma. J Microbiol Biotech Res. 2011;1(3):6671.

81. Fowler JE, Mariano M. Difficulties in quantitating the contribution of methral bacteria to prostatic fluid and seminal fluid cultures. J Urol. 1984;132(3):471-473.

82. Emokpae MA, Uadia PO, Sadiq NM. Contribution of bacterial infection to male infertility in Nigerians. Online Journal of Health and Allied Sciences. 2009;8(1):1-5.

83. Qiang H, Jiang MS, Lin JY, He WM. Influence of enterococci on human sperm membrane in vitro. Asian J Androl. 2007;9(1):77-81. doi:10.1111/j.1745-7262.2007.00219.

84. Menkveld R. Leukocytospermia. In: Daya S, Harrison RF, Kempers RD, eds. Advances in Fertility and Reproductive Medicine. Amsterdam: Elsevier. 2004:218-224.

85. Rybar R, Prinosilova P, Kopecka V, et al. The effect of bacterial contamination of semen on sperm chromatin integrity and standard semen parameters in men from infertile couples. Andrologia. 2012;44(1):410-418. doi:10.11 11/j.1439-0272.2011.01198.

86. Gallegos G, Ramos B, Santiso R, Goyanes V, Gosálvez J, Fernández JL. Sperm DNA fragmentation in infertile men with genitourinary infection by Chlamydia trachomatis and mycoplasma. Fertil Steril. 2008;90(2):328-334. doi:10.1016/j. fertnstert.2007.06.035.

87. González-Marín C, Roy R, López-Fernández C, et al. Bacteria in bovine semen can increase sperm DNA fragmentation rates: a kinetic experimental approach. Anim Reprod Sci. 2011;123(3-4):139-148. doi:10.1016/j. anireprosci.2010.11.014.

88. Steger K. Transcriptional and translational regulation of gene expression in haploid spermatids. Anat Embryol. 1999;199(6):471-487.

89. Braun RE. Packaging paternal chromosomes with protamine. Nat Genet. 2001;28(1):10-12. doi:10.1038/88194.

90. Rathke C, Baarends WM, Awe S, Renkawitz-Pohl R. Chromatin dynamics during spermiogenesis. Biochim Biophys Acta. 2014;1839(3):155-168. doi:10.1016/j. bbagrm.2013.08.004.

91. Jodar M, Oliva R. Protamine alterations in human spermatozoa. Adv Exp Med Biol. 2014;791:83-102. doi:10.1007/978-1-4614-7783-9_6.

92. Dottermusch-Heidel C, Klaus ES, Gonzalez NH, et al. H3K79 methylation directly precedes the histone-to protamine transition in mammalian spermatids and is sensitive to bacterial infections. Andrology. 2014;2(5):655-665. doi:10.1 111/j.2047-2927.2014.00248.

93. Meistrich ML, Trostle-Weige PK, Lin R, Bhatnagar YM, 
Allis CD. Highly acetylated $\mathrm{H} 4$ is associated with histone displacement in rat spermatids. Mol Reprod. 1992;31(1):170181. doi:10.1002/mrd.1080310303.

94. Hazzouri M, Pivot-Pajot C, Faure AK, et al. Regulated hyperacetylation of core histones during mouse spermatogenesis: involvement of histone deacetylases. Eur J Cell Biol. 2000;79(12):950-960. doi:10.1078/0171-933500123.

95. Sonnack V, Failing K, Bergmann M, Steger K. Expression of hyperacetylated histone $\mathrm{H} 4$ during normal and impaired human spermatogenesis. Andrologia. 2002;34(6):384-390. doi:10.1046/j.1439-0272.2002.00524.

96. Rathke C, Baarends WM, Jayaramaiah-Raja S, Bartkuhn M, Renkawitz R, Renkawitz-Pohl R. Transition from a nucleosome-based to a protamine-based chromatin configuration during spermiogenesis in Drosophila. J Cell Sci. 2007;120(9):1689-1700. doi:10.1242/jcs.004663.

97. Gaucher J, Boussouar F, Montellier E, et al. Bromodomain dependent stage-specific male genome programming by Brdt. EMBO J. 2012;31(19):3809-3820. doi:10.1038/ emboj.2012.233.

98. Fenic I, Sonnack V, Failing K, Bergmann M, Steger K. In vivo effects of histone-deacetylase inhibitor trichostatin-A on murine spermatogenesis. J Androl. 2004;25(5):811-818. doi:10.1002/j.1939-4640.2004.tb02859.

99. Burrello N, Calogero AE, Perdichizzi A, Salmeri M, Agata RD, Vicari E. Inhibitation of oocyte fertilization by assisted reproductive techniques and increased sperm DNA fragmentation in the presence of Candida albicans, a case report. Reprod Biomed Online. 2004;8(5):569-573.

100. Calogero AE, La Vignera S, Condorelli RA, Agata RD, Vicari E. Effects of male accessory gland infection on sperm parameters. In: Zini A, Agarwal A, eds. Sperm chromatin, biological and clinical applications in male infertility and assisted reproduction. New York: Springer; 2011; 375-394.

101. Gupta S, Prabha V. Human Sperm Interaction with Staphylococcus aureus: a molecular approach. J Pathog. 2012; 2012: 1-7. doi:10.1155/2012/816536.

102. Prabha V, Aanam, Dhir A, Kaur S. Bacteriological study of the cervix of females suffering from unexplained infertility. Am J Biomed Sci. 2011;3(2):84-89.

103. Nabi A, Khalili MA, Halvaei I, Ghasemzadeh J, Zare E. Seminal bacterial contaminations: Probable factor in unexplained recurrent pregnancy loss. Iran J Reprod Med. 2013;11(11):925-932.

104. Prabha V, Gupta T, Kaur S, Kaur N, Kala S, Singh A. Isolation of a spermatozoal immobilization factor from Staphylococcus aureus filtrates. Can J Microbiol. 2009;55(7):874-878. doi:10.1139/w09-032.

105. Diemer T, Weidner W, Michelmann HW, Schiefer HG, Rovan E, Mayer F. Influence of Escherichia coli on motility parameters of human spermatozoa in vitro. Int J Androl. 1996;19(5):271-7. doi:10.1111/j.1365-2605.1996.tb00475.

106. Diemer T, Uuwc P, Ludwig M,et al. Influence of autogenous leucocytes and Escherichia coli on sperm motility parameters in vitro. Andrologia. 2003;35(2):100-105. doi:10.1046 /j.1439-0272.2003.00523.
107. Erbengi T. Ultrastructural observations on the entry of Chlamydia trachomatis into human spermatozoa. Hum Reprod. 1993;8(3):416-421.

108. Schulz M, Sanchez R, Solo L, Risopatrón J, Villegas J. Effect of Escherichia coli and its soluble factors on mitochondrial membrane potential, phosphatidylserine translocation, viability and motility of human spermatozoa. Fertil Steril. 2010;94(2):619-623. doi:10.1016/j.fertnstert.2009.01.140.

109. Barbonetti A, Vassallo MR, Cinque B, et al. Soluble products of Escherichia coli induce mitochondrial dysfunction-related sperm membrane lipid peroxidation which is prevented by lactobacilli. PLoS One. 2013;8(12):e83136. doi:10.1371/ journal.pone.0083136.

110. Prabha V, Sandhu R, Kaur S, et al. Mechanism of sperm immobilization by Escherichia coli. Adv Urol. 2010;2010:240268. doi:10.1155/2010/240268.

111. Edwards JL, Apicella MA. The molecular mechanisms used by Neisseria gonorrhoeae to initiate infection differ between men and women. Clin Microbiol Rev. 2004;17(4):965-981. doi:10.1128/CMR.17.4.965-981.2004

112. Anderson MT, Dewenter L, Maier B, Seifert HS. Seminal plasma initiates a Neisseria gonorrhoeae transmission state. MBio. 2004;5(2):e01004-13. doi:10.1128/mBio.01004-13

113. Gomez CI, Stenback WA, James AN, Criswell BS, Williams RP. Attachment of Neisseria gonorrhoeae to human sperm. Microscopical study of trypsin and iron. BrJ Vener Dis. 1979; 55 (4): 245-255.

114. Stohl EA, Chan YA, Hackett KT, Kohler PL, Dillard JP, Seifert HS. The Neisseria gonorrhoeae virulence factor NG1686 is a bifunctional M23B family metallopeptidase that influences resistance to hydrogen peroxide and colony morphology. J Biol Chem. 2012;287(14):11222-11233. doi:10.1074/jbc. M111.338830

115. Liu JH, Li HY, Cao ZG, Duan YF, Li Y, Ye ZQ. Influence of several uropathogenic microorganisms on human sperm motility parameters in vitro. Asian J Androl. 2002;4(3):179182.

116. Zhang ZH, Zhang HG, Dong Y, Han RR, Dai RL, Liu RZ. Ureaplasma urealyticum in male infertility in Jilin Province, North-east China, and its relationship with sperm morphology. J Int Med Res. 2011;39(1):33-40. doi:10.1177/147323001103900104

117. Zbeng J, Yu SY, Jia DS, et al. Ureaplasma urealyticum infection in the genital tract reduces seminal quality in infertile men. Zhonghua Nan Ke Xue. 2008;14(6):507-512.

118. Kohn FM, Erdmann I, Oeda T, el Mulla KF, Schiefer HG, Schill WB. Influence of urogenital infections on sperm functions. Andrologia. 1998;30(1):73-80. doi:10.1111/j.1439-0272.1998.tb02829.

119. Wan CC, Wang H, Hao BJ, Shang XJ, Huang YF. Infection of Chlamydia trachomatis and apoptosis of spermatogenic cells. Zhonghua Nan Ke Xue. 2003;9(5):350-351.

120. Al-Janabi AO, Jubair AS, Pemmaraju SC, Pruthi PA, Pruthi $\mathrm{V}$. The role of bacterial infections on male infertility in AlAnbar province of Iraq. Int J Med Sci Public Health. 2014;3 (2):177-180.

Copyright (C) 2017 The Author (s); This is an open-access article distributed under the terms of the Creative Commons Attribution License (http://creativecommons.org/licenses/by/4.0), which permits unrestricted use, distribution, and reproduction in any medium, provided the original work is properly cited. 